\title{
Effects of a Low-oestrogen Oral Contraceptive on Urinary Excretion of Luteinizing Hormone and Ovarian Steroids
}

\author{
MAX ELSTEIN, P. G. BRISTON, M. JENKINS, \\ D. KIRK, H. MILLER
}

British Medical fournal, 1974, 1, 11-13

\section{Summary}

The urinary gonadotrophin and ovarian steroid excretion pattern was studied in five women taking an oral contraceptive formulation consisting of mestranol $50 \mu \mathrm{g}$ and norethisterone $1 \mathrm{mg}$. Both the pretreatment and posttreatment cycles were normal. The ovulatory peak of luteinizing hormone (LH) during the treatment cycles was uniformly suppressed, but LH continued to be excreted within the normal range. In one fifth of the treatment cycles there was a pronounced and sustained rise of oestrogen output in the absence of ovulation, and in many of the other treatment cycles oestrogen levels suggested that active ovarian steroidogenesis was taking place.

\section{Introduction}

The association of the incidence of thromboembolism with the amount of oestrogen in a combined oral contraceptive formulation (Inman et al., 1970) resulted in the Committee on Safety of Medicines recommending that the oestrogen content should not exceed $50 \mu \mathrm{g}$. Epidemiological data since these recommendations were implemented suggest that their advice was sound (Adelstein, 1972). However, with the tendency to decrease the content of progestogen as well, there was a risk that suppression of pituitary-ovarian function might not be as effective as with the higher-dose combined formulations (Loraine and Bell, 1966; Orr and Elstein, 1969) and that the ancillary contraceptive effects in the genital tract (Diczfalusy, 1965) might not be adequate to provide local antifertility protection in the event of break-through ovulation.

Detailed studies of the hormone excretion pattern of the socalled "balanced" formulations comprising $1 \mathrm{mg}$ of a 19-nor steroid and $50 \mu \mathrm{g}$ of oestrogen have not, so far as we are aware, been published. The following study of the urinary excretion of pituitary luteinizing hormone and ovarian steroids was made in women taking a combined oral contraceptive formulation consisting of $1 \mathrm{mg}$ norethisterone and $50 \mathrm{~kg}$ mestranol (OrthoNovin $1 / 50$ ).

\section{Materials and Methods}

Five healthy women in their active reproductive years with proved fertility were studied over four cycles. Complete 24-hour urine samples were collected throughout the period of investiga-

\footnotetext{
Department of Human Reproduction and Obstetrics, University of Southampton, Southampton SO1 6HU

MAX ELSTEIN, M.D., M.R.C.o.G., Senior Lecturer

Endocrine Laboratory, Portsmouth and Isle of Wight Area Pathology Service, St. Mary's General Hospital, Portsmouth PO3 6AG P. G. BRISTON, B.SC., Biochemist

M. JENKINS, B.S., A.I.M.L.T., Technician

D. KIRK, M.SC., Senior Biochemist

H. MILLER, M.D., F.R.C.PATH., Senior Pathologist
}

tion. After one normal menstrual cycle, which served as a control, two cycles were observed when the combined oral contraceptive was taken, and in all but one volunteer a further post-treatment cycle was studied. Oral basal body temperatures were charted throughout the period of observation, episodes of bleeding were recorded, and subjective symptoms were noted.

Hormone Assays.-Luteinizing hormone (LH) was measured by radioimmunoassay for human chorionic gonadotrophin and LH (Wilde et al., 1967) against a laboratory substandard of the Second International Reference Preparation of human menopausal gonadotrophin and expressed as IU of $\mathrm{LH} / 24 \mathrm{hr}$. Total oestrogens were assayed by the semi-automatic rapid method of Brown et al. (1968). Pregnanediol and pregnanetriol were determined by a gas chromatographic method (Crook, 1972).

\section{Results}

The hormone excretion pattern of these five subjects is shown in figs. 1 to 5 .

In the normal pretreatment control cycles the urinary $\mathrm{LH}$ and ovarian steroid output was similar to that already described (Orr and Elstein, 1969; Brown and Beischer, 1972). After withdrawal of the oral contraceptives the pattern in the posttreatment cycles closely resembled those in the controls.

During the treatment cycles there was a consistent loss of the mid-cycle peak of $\mathrm{LH}$ excretion which, however, maintained a constant level at about 30 to $40 \mathrm{IU} / 24 \mathrm{hr}$. This suggested that the tonic release of $\mathrm{LH}$ was not affected by this medication but that only the ovulatory surge of $\mathrm{LH}$ was inhibited.

Pregnanediol and pregnanetriol levels were uniformly suppressed while these pills were taken cyclically, indicating that ovulation did not occur during these 10 treatment cycles.

Two patterns of oestrogen excretion were obtained. There were two treatment cycles with markedly raised levels of urinary oestrogen. In the second treatment cycle of subject 1 the output of oestrogen reached a mid-cycle peak of over $120 \mu \mathrm{g} / 24 \mathrm{hr}$ which was twice that of the pretreatment and post-treatment cycles. The total urinary oestrogen output in this cycle more

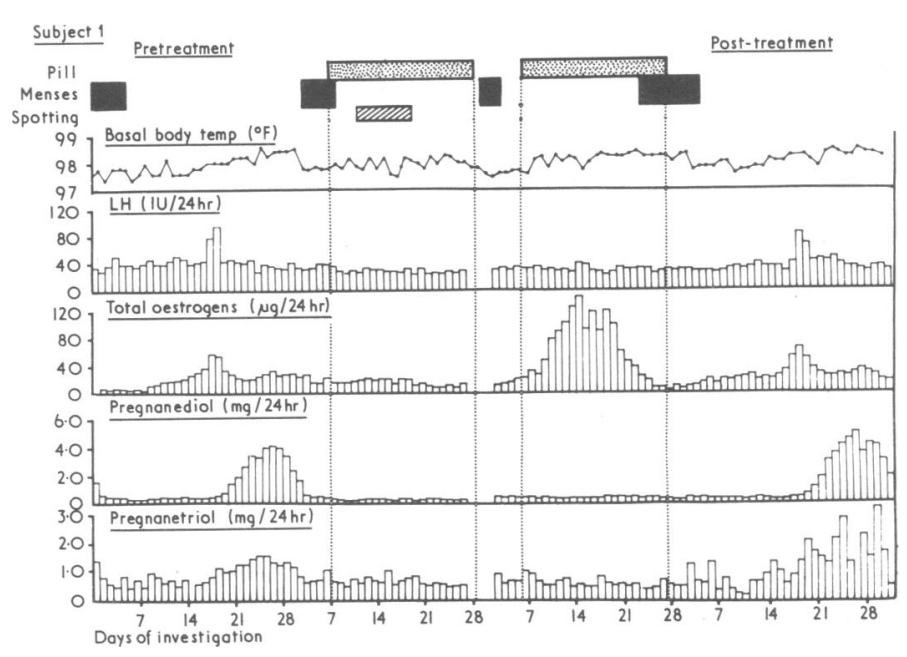

FIG. 1-Hormone excretion pattern in the five subjects during period of study. 


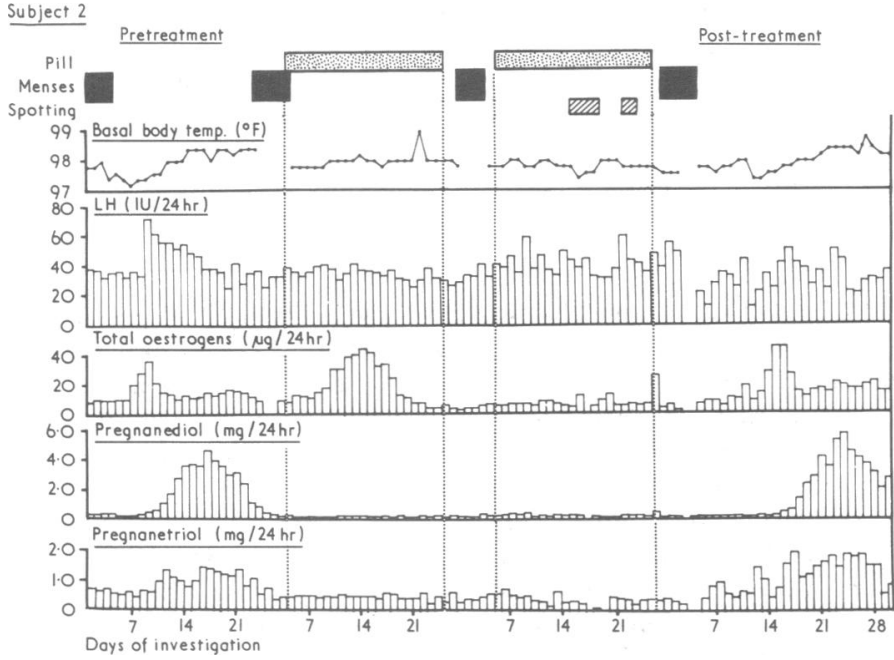

FIG. 2-Hormone excretion pattern in the five subjects during period of study.

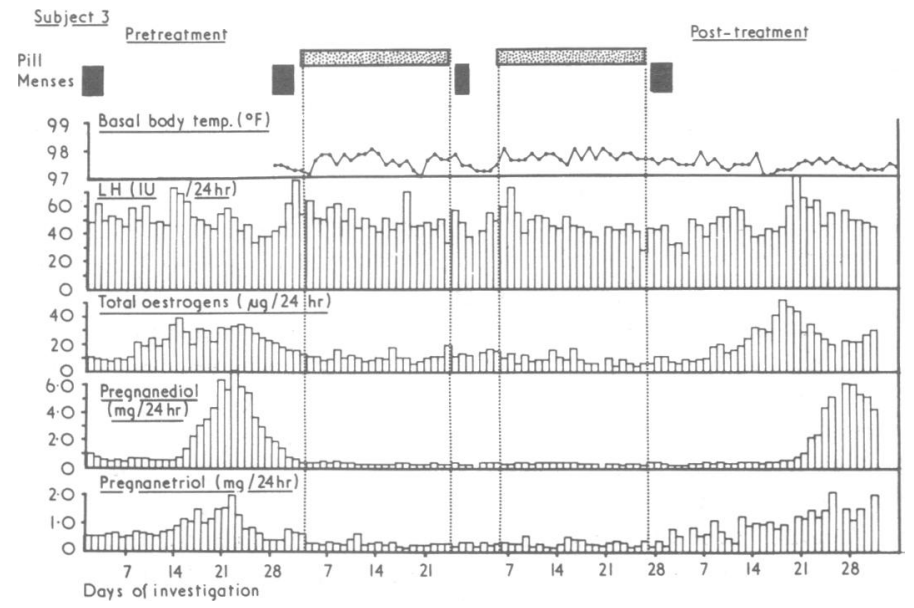

FIG. 3-Hormone excretion pattern in the five subjects during period of study.

than doubled that in her cycles when this oral contraceptive was not taken (fig. 1). The other cycle in which there was an increased output of oestrogen was during the first treatment course of subject 2 . Here there was a mid-cycle maximum of $40 \mu \mathrm{g}$ of oestrogen which was of a similar magnitude to her ovulatory peak, and again the total output during this cycle was greater than in the two non-treatment cycles (fig. 2). In the other treatment cycles of these two subjects and in all the treatment cycles of the other three subjects the level of urinary oestrogen remained below $20 \mu \mathrm{g} / 24 \mathrm{hr}$ but did not fall below $10 \mu \mathrm{g} / 24 \mathrm{hr}$ to any extent except occasionally in three of the remaining eight treatment cycles. These data suggest that pronounced ovarian steroidogenesis in the absence of ovulation occurred in two of these women and that some ovarian activity was present in most treatment cycles.

There were no subjective symptoms during those cycles in which there were raised oestrogen levels. In four of the treatment cycles three of the subjects complained of vague symptoms such as tiredness, feeling bloated, and aching legs. Subject 1 complained of these symptoms in the cycle preceding that in which there was the markedly increased oestrogen output. It is doubtful if these symptoms have any relation to the endocrine pattern, and their significance has been discussed elsewhere (Bye and Elstein, 1973).

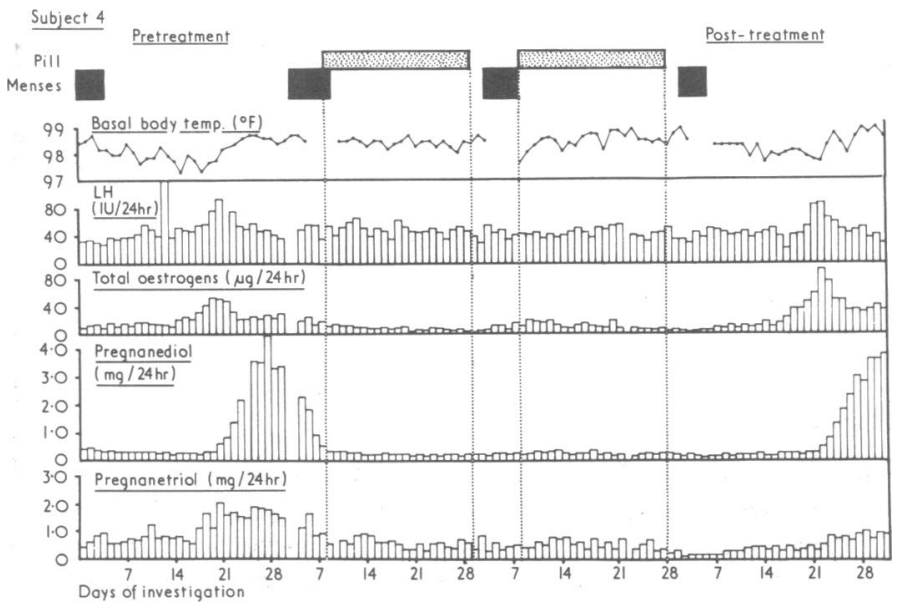

FIG. 4-Hormone excretion pattern in the five subjects during period of study.

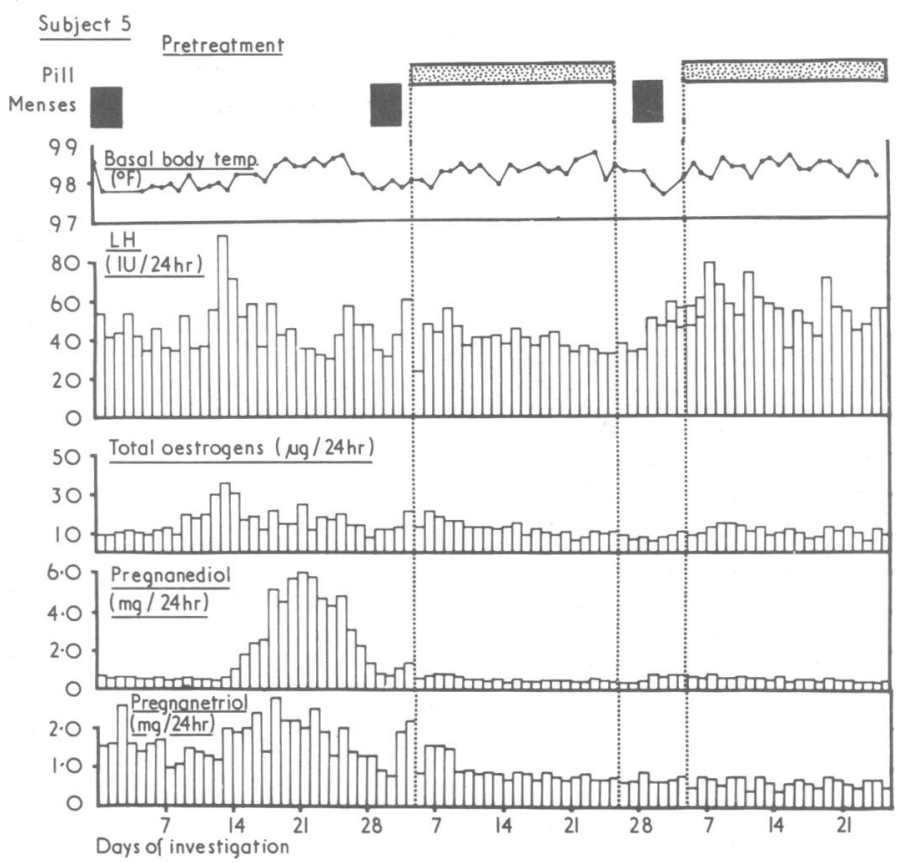

FIG. 5-Hormone excretion pattern in the five subjects during period of study.

\section{Discussion}

The results of this study show that this low-dose combined oral contraceptive effectively suppresses the mid-cycle LH peak as observed with the higher-dose formulations (Orr and Elstein, 1969). In only some of these "first generation" oral contraceptives, however, was there appreciable excretion of gonadotrophins (Loraine and Bell, 1966), whereas in all 10 cycles when this contraceptive was taken the level of $\mathrm{LH}$ remained within the normal non-ovulatory range, suggesting that pituitary inhibition was not severe. This is supported by the findings in the posttreatment cycles in which the ovulatory $\mathrm{LH}$ peak was not delayed and, in contrast to those after long-term use of the higher-dose formulations, the endocrine pattern was not dissimilar to that in the control cycles (Bell and Loraine, 1967; Elstein, 1969).

The oestrogen output during the administration of these oral contraceptives shows that ovarian steroidogenesis was occurring, and the raised levels of oestrogen in the absence of ovulation in the occasional cycle indicates highly active ovaries, suggestive of 
appreciable follicular development. It may be that the margin of contraceptive effectiveness of this lower-dose formulation is less than that of earlier preparations. There were no untoward clinical findings during the two high oestrogen output cycles. It would be very difficult to determine clinically the incidence of contraceptive cycles in which the output of oestrogen was raised. Nevertheless, the fact that such high levels of endogenous oestrogen output does occur during the administration of a lower-oestrogen-containing oral contraceptive raises the question whether it is indeed the dose of oestrogen per se which bears a relation to the incidence of thromboembolism. Clearly, the combination of a particular progestogen with the oestrogen has some, as yet undetermined, influence on this, as the lower incidence of thromboembolism with the combined pill comprising norethynodrel and mestranol would suggest (Inman et al., 1970).

The recommendations of the Committee on Safety of Medicines were related to a fixed dose of both types of oestrogen currently found in combined oral contraceptive formulations, even though ethinyl oestradiol has a greater oestrogenic action in humans than that of mestranol (Delforge and Ferin, 1970). There are other differences in the effect of these two oestrogens on carbohydrate metabolism (Di Paola et al., 1968), liver function (Eisalo et al., 1968), and also vitamin $B_{6}$ metabolism (Luhby et al., 1971). Clearly, further studies of a similar nature to this with a combined contraceptive formulation comprising ethinyl oestradiol instead of mestranol at a dose of $50 \mu \mathrm{g}$ or even less and $1 \mathrm{mg}$ of norethisterone will provide further interesting data, and these studies are under way.

We are pleased to acknowledge the help of Mrs. Sheila Adcock, the administrative sister of the Southampton University Contraceptive Research Clinics, who supervised the collection of the specimens from our five volunteers who co-operated so well in the study. We also acknowledge the technical help of Miss $B$. Purdie and Mr. Martin Slater, who processed the urine and arranged its transport to Portsmouth.

We are grateful to Dr. Neville Shephard of Ortho Pharmaceutical, Ltd., who encouraged the study and arranged a generous grant. We are also indebted to the Wessex Regional Hospital Board for financial support.

\section{References}

Adelstein, A. M. (1972). Health Trends, 4, 2.

Bell, E. T., et al. (1967). Acta Endocrinologica, Copenhagen, 54, 96 Bell, E. T., and Loraine, J. A. (1967). Lancet, 2, 442.

Brown, J. B., MacLeod, S. C., Macnaughton, C., Smith, M. A., and Smyth, B. (1968). Journal of Endocrinology, 42, 5 .

Brown, J. B., and Beischer, N. A. (1972). Obstetric and Gynecological Survey, $27,205$.

Bye, P., and Elstein, M. (1973). British Medical fournal, 2, 389.

Crook, D. (1972). Clinica Chimica Acta, 40, 43.

Delforge, J. P., and Ferin, J. (1970). Contraception, 1, 57.

Diczfalusy, E. (1965). British Medical fournal, 2, 1394.

Di Paola, G., Puchula, F., Robin, M., Nicholson, R., and Marti, M. (1968) American fournal of Obstetrics and Gynecology, 101, 206.

Eisalo, A., Heino, A., and Räsänen, V. (1968). Acta Obstetricia et Gynecologica Scandinavica, 47,58 .

Elstein, M. (1969). In Chlormadinone Acetate, a New Departure in Oral Contraception, p. 47. Amsterdam, Excerpta Medica Foundation.

Contraception, p. 47. Amsterdam, Excerpta Medica Foundation.
Inman, W. H. W'., Vessey, M. P., Westerholm, B., and Engelund, A. (1970) British Medical fournal, 2,203 .

Loraine, J. A., and Bell, E. T. (1966). In Hormone Assays and their Clinical Application, p. 511. Edinburgh, Livingstone.

Luhby, A. L., et al. (1971). American fournal of Clinical Nutrition, 24, 684.

Orr, A. H., and Elstein, M. (1969). Fournal of Endocrinology, 43, 617.

Wilde, C. E., Orr, A. H., and Bagshawe, K. D. (1967). Fournal of Endocrinology, 37, 23.

\title{
Closing Volume and Pregnancy
}

\author{
D. R. BEVAN， ANITA HOLDCROFT， L. LOH，W. G. MACGREGOR， J. C. O'SULLIVAN, \\ M. K. SYKES
}

British Medical fournal, 1974, 1, 13-15

\section{Introduction}

The changes in maternal ventilation which occur during pregnancy are now well established. Increases in minute volume and oxygen consumption are seen from early pregnancy (MagnusLevy, 1904). The increase in minute volume, which seems to be an accentuation of the normal changes occurring during the menstrual cycle, may result in a progressive fall in the arterial $\mathrm{PCO}_{2}$ during pregnancy (Prowse and Gaensler, 1965). These changes are probably due to hormonal secretion as they occur before the increased demand of the fetus appears.

Changes in lung volumes occur only during the last trimester. Though there is little change in vital capacity there are considerable falls in expiratory reserve volume and residual volume (RV) and consequently in functional residual capacity (FRC) (Cugell et al., 1953). These changes are due to the mechanical presence of an intra-abdominal tumour tending to force the diaphragm into the chest.

Reported measurements of maternal arterial oxygen tension show wide variation. Despite the hypocapnia they tend to be lower than in non-pregnant women of the same age (Stenger et al., 1964). The cause of this fall in arterial oxygenation is unknown but has been attributed to cardiovascular and respiratory disturbances (Ang et al., 1969). A fall in FRC in other situations-for example, after surgery (Craig et al., 1971; Alexander et al., 1972)-results in impaired distribution of pulmonary ventilation. This impaired distribution may be detected by measurement of the "clsoing volume" which is the lung volume during expiration at which airways begin to close

(P.A. R.C.S., Senior Registrar, Department of Anaesth London W.C.1)

W. G. MACGREGOR, F.R.C.S., F.R.C.O.G. Reader, Department of Obstetrics J. C. O'SULLIVAN, F.R.C.S., M.R.c.o.G., Senior Registrar, Department of

M. K. SYKES, M.B., F.F.A. R.C.s., Professor of Clinical Anaesthesia 